БОЛЬШАКОВА Юлия Михайловна - кандидат политических наук, доцент кафедры государственного и муниципального управления Коми республиканской академии государственной службы и управления (167000, Россия, Республика Коми, г. Сыктывкар, Коммунистическая ул., 11, асадету. prof.com@gmail.com)

\title{
ОТ ГОСУДАРСТВЕННЫХ УСЛУГ К ГОСУДАРСТВЕННОМУ СЕРВИСУ: К СОЦИОЛОГИИ СОВРЕМЕННОГО ГОСУДАРСТВЕННОГО УПРАВЛЕНИЯ
}

\begin{abstract}
Аннотация. В статье рассматриваются и решаются на основе применения принципов социологии управления основные проблемы и стоящие за ними противоречия, возникающие в процессе институционализации государственного сервиса: противоречие между формальным характером института государственных услуг и требованием «неформальности» услуги; противоречие между монопольным характером производства государственных услуг и требованием клиентоориентированности; проблема поддержания консенсуса между производителем и потребителем государственных услуг в постоянно меняющихся внешних условиях; проблема управления импортом сервисной модели в условиях догоняющей модернизации.

Ключевые слова: государственный сервис, государственная услуга, трансакционная услуга, институционализация государственного сервиса, патронажно-сервисная модель государства, дружественный сервис-интерфейс
\end{abstract}

$\Pi$ ервое, с чем сталкивается исследователь современных тенденций в управлении обществом, и в частности при интерпретации этого управления в формате государственных услуг, - это неопределенность самого понятия «государственная услуга». Свою лепту в эту неопределенность в условиях российской действительности внес федеральный закон «Об организации предоставления государственных и муниципальных услуг». Согласно этому закону, «государственные (муниципальные) услуги - это услуги, которые предоставляются физическим лицам и организациям по их запросу федеральными органами исполнительной власти, исполнительными органами государственной власти субъектов Российской Федерации, органами управления государственных внебюджетных фондов Российской Федерации или местными администрациями в рамках их компетенции» ${ }^{1}$.

Не преследуя цели всеобъемлющего устранения этой неопределенности в рамках данной статьи, укажем все же, что круг оказываемых государственных услуг населению шире, чем тот, который охватывается данным законом. Как следует из этого определения, в нем идет речь о так называемых услугах трансакционного типа [Владиславлев 2010: 49] (административных, титульных), в отличие от другого типа услуг, также оказываемых государством, которые по аналогии с соответствующим типом благ можно назвать трансформационными.

Если трансформационные услуги связаны с непосредственным удовлетворением физических (материальных) и духовных потребностей людей (услуги здравоохранения, образовательные услуги), то услуги трансакционного типа заключаются в документированном подтверждении различного рода гражданских прав, в т.ч. и на получение трансформационных услуг. Трансакционные услуги играют разрешительную роль по отношению к трансформационным

\footnotetext{
1 Федеральный закон «Об организации предоставления государственных и муниципальных услуг» от 27.07.2010 N 210-Ф3 (посл. ред.). Доступ: http://www.consultant.ru/document/cons_doc_LAW_103023/
} 
услугам, выполняя распределительную функцию государства. Трансакционные услуги носят, таким образом, характер управленческих, поскольку в существенной степени регулируют социальную жизнь граждан.

Вообще следует сказать, что в репутационном плане сфера государственных услуг занимает совершенно особое место. Благодаря тому что взаимодействие государства и общества в этой сфере носит контактный, систематический и интенсивный характер, формирующиеся отношения между государством и обществом находят здесь свое концентрированное выражение, а сама сфера государственных услуг предстает в глазах общества своего рода «лицом» государства. Таким образом, возникает закономерный вопрос: каким образом и на основе каких подходов может быть радикальным образом повышено качество государственного управления в целом и качество государственных услуг в частности?

Из анализа факторов, актуализирующих модернизацию государственного управления и его подсистем, нетрудно выделить одну общую черту - возрастание относительной сложности объекта управления (относительно сложности субъекта) и на этом фоне все более отчетливое эксплицирование такого фундаментального свойства социальной системы, как человекоразмерность. Это обстоятельство делает безальтернативным применение для решения рассматриваемой проблемы социолого-управленческого подхода. Следует признать вместе с тем, что существует традиционно скептическое отношение к применению социологии управления к системам макроуровня (типа систем «государство - общество»). Прежде чем приступить к анализу проблем, связанных с применением указанного подхода, следует рассмотреть дополнительно два вопроса. Первый из них связан с анализом современного состояния социологии управления. Для того чтобы сделать это, необходимо понять, на каком этапе парадигмальной эволюции этой дисциплины мы находимся. Для упрощения анализа воспользуемся аналогией между социологией управления и институциональной экономикой, продвинувшейся в своем эволюционном развитии существенно дальше.

Как известно, основными постулатами теории рационального выбора, лежащей в основе неоклассической экономики, являются постулаты о полной рациональности субъекта экономического обмена, о полноте и доступности всей информации о рынке и, как следствие, об отсутствии трансакционных издержек (трения) при совершении сделок [Кулакова 2012: 100]. По мере усложнения задач экономического обмена редукционистские представления неоклассики (классическая парадигма) приводили к совершенно неудовлетворительным результатам. Пришлось отказаться от упомянутых постулатов, признать ограниченную рациональность субъектов рынка и существование ненулевых трансакционных издержек. Это привело к рождению неоинституциональной теории и означало переход от классической парадигмы экономического рынка к неклассической. На этом этапе важно отметить признание институтов как инструментов координации поведения экономических агентов и минимизации, таким образом, трансакционных издержек. Эта задача решалась путем формирования таких правил взаимодействия, в отношении которых достигался консенсус институциональных агентов. Сформированные таким образом правила, дополненные специально создаваемыми механизмами принуждения к их исполнению, собственно, и представляют собой институт. Пришедшая на смену неклассической постнеклассическая парадигма, признав роль и значение институтов, внесла свой вклад в развитие институциональной экономической теории, эксплицировав неравновесность и нелинейность экономического рынка. Аналогичные этапы парадигмальной эволюции можно разглядеть и в историческом развитии управления социальными системами. 
Так, исходящий из редукционистских представлений о полной рациональности субъекта управления, возможности полной формализации поведения объекта и, следовательно, его неограниченной управляемости административный, линейный тип управления можно соотнести с классическим этапом парадигмальной эволюции. Проявившаяся в условиях все возрастающей сложности объекта ограниченность административного управления заставила отказаться от идеи полной рациональности субъекта и неограниченной управляемости объекта управления, признать наличие ненулевых интеракционных издержек (своего рода социальной вязкости, социального трения) и, следовательно, необходимость институтов управления как инструментов скоординированного взаимодействия участников управленческого процесса и минимизации интеракционных издержек в этом процессе.

При этом управление заняло как бы промежуточное положение [Тихонов 2009: 10]: с одной стороны, направленность итерационной процедуры на достижение консенсуса означает отказ от властно-административного диктата, а с другой - сохраняющаяся активная роль субъекта, организующего и контролирующего итерационную процедуру формирования институциональных правил, не позволяет раствориться управлению в самоорганизующемся процессе.

Итак, можно говорить о вступлении государственного управления в фазу перехода от классической к неклассической (институциональной) парадигме. Это мы и будем иметь в виду, говоря о современном понимании социологии управления применительно к государственному управлению.

Исходя из сказанного, институт государственного сервиса можно определить как норму взаимодействия государства и общества (как субъектов процесса производства - потребления государственных услуг), имеющую целью достижение и поддержание (благодаря обратной связи) консенсуса государства и общества в указанной сфере.

Второй вопрос, требующий дополнительного уточнения, касается терминов «государственная услуга» и «государственный сервис», употребляемых нами в оппозиции друг другу. Кардинальное различие понятий, обозначаемых этими терминами, заключается в том, что они являются производными продуктами институтов двух разных типов, двух разных механизмов формирования институциональных правил и двух разных механизмов обеспечения соответствующего качества производимых государственных услуг. Государственный сервис - продукт, производимый институтом государственного сервиса, формирование институциональных правил которого и обеспечение высокого качества государственных услуг осуществляются на основе итерационно-консенсуального механизма. Государственный сервис можно определить как продукт субъектсубъектных отношений производителя и потребителя услуг.

В свою очередь, государственная услуга может рассматриваться как продукт субъект-объектных отношений и как продукт функционирования института, находящегося (в условиях несоответствия сложности объекта и субъекта управления) в патологическом состоянии вырождения.

При этом понятно, что в развитой фазе сферы государственных услуг эти понятия становятся тождественными, а соответствующие термины - синонимами. Но в переходном периоде, переживаемом странами догоняющей модернизации, когда имеет место сосуществование и государственного сервиса, и государственных услуг в рассмотренном понимании, терминологическое различение представляется методологически оправданным.

Теперь мы можем приступить к непосредственному рассмотрению теоретических и практических проблем, связанных с применением социологического 
подхода к макросистемам, а следовательно, как уже отмечалось, к институционализации государственного сервиса.

Из приведенного определения института государственного сервиса следует, что произведенная этим институтом услуга носит в содержательном плане неформальный характер. В то же время сам институт является сугубо формальным в отношении формы: его институциональные правила вербализованы, зафиксированы в письменной форме и санкционированы государством. Так как функция является содержательной характеристикой института и в данном случае состоит в производстве неформальной услуги, то в содержательном плане и институт государственного сервиса должен быть неформальным, оставаясь формальным в отношении формы.

Между тем существующая типология институтов постулирует, что формальные в отношении формы институты имеют и формальное содержание [Норт 1997] и наоборот. Таким образом, институту государственного сервиса с его сущностным признаком - принадлежностью к формально-неформальному типу места не находится. В этом заключается главное теоретическое противоречие, принципиально требующее своего разрешения, причем в рамках породившей это противоречие теории. Для преодоления такого рода противоречия нами разработана бихарактеристическая типология институтов, которая характеризует их и в отношении формы, и в отношении содержания [Большакова 2015]. Указанная типология обладает большей исследовательской разрешающей способностью, позволяющей «разглядеть» также промежуточные типы институтов, в частности формально-неформальный, который выражает собой сущностный признак института государственного сервиса. Таким образом, теоретическую возможность существования этого института можно считать доказанной.

Неформальность содержания институтов и, соответственно, производимой им услуги означает, что существует консенсус государства и общества в отношении правил взаимодействия их в данной сфере. Достижение этого консенсуса должно осуществляться в результате итерационной процедуры по корректировке правил, осуществляемой посредством механизма обратной связи по инициативе и под контролем государства как доминирующего субъекта управления. Совокупность правил, а также организационно-технических, материальных и информационных средств, реализующих эти правила, может быть интерпретирована как сервис-интерфейс между государством и обществом в сфере производства - потребления государственных услуг. Развивая эту метафору, неформальное содержание института и неформальность производимой им услуги следует трактовать как дружественность сервис-интерфейса. Следующий вопрос заключается в том, каковы условия практической реализации дружественного сервис-интерфейса, который вместе с участниками управленческого процесса (государство и общество) и образует институт государственного сервиса. Здесь мы сталкиваемся с еще одним противоречием, порождаемым монопольным характером производства государственных услуг.

Отметим сразу, что дружественность государственных услуг не может быть достигнута в рамках чисто экономических отношений государства и общества, ведь монополия государства на производство государственных услуг полностью лишает его мотивации идти на издержки для решения указанной задачи. Однако ситуация в корне меняется, если мы примем во внимание фактор репутации государства, поскольку состояние сферы государственных услуг выступает важным показателем способности власти проводить курс на модернизацию.

Так возникает новая норма взаимодействия государства и общества в сфере государственных услуг. При этом указанная норма обладает следующими особенностями: эта норма является синтетической, т.к. государство и общество 
выступают как участники не только экономического, но и политического соглашения. Эта норма отличается также более симметричной матрицей полезности, которая определяет правовые позиции сторон. Сказанное означает включенность государства и общества в общий конур взаимодействия, охваченный отрицательной обратной связью, «жесткость» которой определяется преимущественно электоральным значением репутационного фактора.

Следует различать два контура обратной связи. Контур короткого маршрута включает в себя государство, представленное бюрократией среднего и нижнего звена, институт государственного сервиса (интерфейс между государством и обществом) и общество. Контур «длинного маршрута» включает в себя также государство, представленное верховной властью. В отсутствие контура «длинного маршрута» обратная связь в контуре «короткого маршрута» чаще всего приобретает формальный характер и реально не работает. Возрастание роли качества государственных и муниципальных услуг как электорально-репутационного фактора заставляет верховную власть озаботиться проблемой радикального и притом реального увеличения качества этих услуг. Это и означает включенность государства в контур обратной связи «длинного маршрута».

Следующая проблема заключается в поддержании в актуальном состоянии дружественности сервис-интерфейса, что требует непрерывной искусной и тонкой его настройки.

Как задача реализации обратной связи, так и задача поддержания в актуальном состоянии дружественности сервис-интерфейса находят свое продолжение в более частных проблемах формирования адекватного сигнала обратной связи и его трансформирования в управляющий сигнал. Первая проблема обусловлена спецификой услуги как производимого блага, качество которого определяется материальными факторами, которые можно измерить, и нематериальными, измерению не поддающимися. Поэтому, помимо оценки качества услуги посредством стандартов, востребованным оказался и такой инструмент, как показатель удовлетворенности потребителя. Достаточно условно первый способ можно охарактеризовать как формальный, второй - как содержательный. Пожалуй, главным недостатком оценки качества услуги посредством стандартов является возникновение эффекта, который можно назвать парадоксом роста качества услуги. Являясь по своей природе формальным правилом, стандарт качества с течением времени утрачивает свою актуальность (если своевременно не происходит его корректировка), вступая в фазу институциональной деградации. При этом чем последовательнее проводятся меры по приведению качества в соответствие с этим правилом (стандартом), что и фиксируется формально по возрастающему уровню этого соответствия, тем ниже оценки качества, производимые на основе удовлетворенности. С другой стороны, не свободен от недостатков в качестве инструмента оценки качества и показатель удовлетворенности, главным из которых является его субъективный характер.

Вот почему целесообразным представляется их совместное взаимодополняющее использование. Например, проявление парадокса роста качества услуги может служить индикатором утраты стандартом качества своей актуальности.

Не менее важной представляется проблема, вытекающая из социокультурного контекста, в котором осуществляется модернизация указанной сферы. Рассмотрим этот вопрос применительно к российским условиям.

Уместно в этой связи напомнить, что реформирование сферы государственных и муниципальных услуг началось как составная часть административной реформы. Это реформирование производилось под флагом реализации сервисной модели государства и вызвало полемику [Якунин, Сулашкин 2012: 105]. Одна из существенных проблем институционального импорта сервисной 
модели состоит в совмещении рыночной логики производства и потребления услуги с государственно-административным характером сферы государственного и муниципального управления, тяготеющей к монополизации, а в модернизирующихся странах - еще и к патернализму. Совмещение двух режимов функционирования (рыночного и административного) создает много проблем как теоретического, так и практического характера.

В качестве альтернативы сервисной модели государства может быть предложена патронажно-сервисная модель государства, которая структурирует пространство взаимодействия государства и общества на, условно говоря, целерациональную и ценностно-рациональную области. И только в первой из них реализуется сервисная модель, тогда как вторая ревизии не подвергается. Эта модель представляется не только примером управления модернизационным процессом в духе постнеклассической парадигмы, но и попыткой синтеза моделей так называемого сильного государства и сервисного государства. Что же касается ее дальнейшей судьбы, то она вверяется институциональной эволюции.

Рассмотренные в рамках данной статьи вопросы, разумеется, не исчерпывают всю проблематику, связанную с данной темой. Тем не менее они дают достаточно отчетливое представление как о перспективах социологического подхода к государственному управлению, так и о трудностях, стоящих на этом направлении.

Можно сделать вывод, что, несмотря на существующие трудности, применение социологического подхода к государственному управлению имеет вполне ясную перспективу. Нельзя не отметить и следующее: в связи с необходимостью преодоления системного кризиса, переживаемого современным государственным управлением в последнее время, много говорится о так называемом аксиологическом повороте [Волкова 2013]. На наш взгляд, амплитуда такого поворота представляется чрезмерной. Это означало бы переход из одной крайности в другую. Если и говорить о повороте в государственном управлении, то о повороте социологическом, органично сочетающем и рационально-технологический, и социокультурный аспекты социологии управления, что актуализирует развитие в рамках последней нового направления - социологии современного государственного управления.

\section{Список литературы}

Большакова Ю.М. 2015. Проблема соотношения формальных и неформальных норм в институционализме и бихарактеристический подход к типологии институтов. - Теория и практика общественного развития. № 13. С. 21-24.

Владиславлев Д.Н. 2010. Понятие трансакционной услуги, виды трансакционных услуг. - Экономические науки. № 10(71). С. 47-50.

Волкова А.В. 2013. Публичные ценности и система государственного управления в России. СПб: Изд-во СПбГУ. 384 с.

Кулакова Т.А. 2012. Трансформация понятия «рациональное» в теории принятия решений в политике и управлении. - Исторические, философские, политические и юридические науки, культурология и искусствоведение. Вопросы теории и практики. № 1. С. 98-103.

Норт Д. 1997. Институты, институциональные изменения и функционирование экономики. М.: Фонд экономической книги «Начала». 180 с.

Тихонов А.В. 2009. От социологии менеджмента к социологии управления как научно-исследовательской программе. - Социология власти. № 7. С. 7-16.

Якунин В.И., Сулашкин С.С. 2012. Постиндустриализм: опыт критического анализа. М.: Научный эксперт. 288 с. 
BOL'SHAKOVA Yuliya Mikhailovna, Cand.Sci. (Pol.Sci.), Associate Professor of the Chair of State and Municipal Administration, Komi Republican Academy of Public Administration and Management (11 Kommunisticheskaya St, Syktyvkar, Komi Republic, Russia, 167000; academy.prof.com@gmail.com)

\title{
FROM STATE SERVICE TO THE INSTITUTE OF PUBLIC SERVICES: TO THE SOCIOLOGY OF MODERN PUBLIC MANAGEMENT
}

\begin{abstract}
The article considers the following main problems and the contradictions that arise in the process of the institutionalization of public service: the contradiction between the formal character of the institution of public services and the requirement of informality of the service; the contradiction between the monopolistic nature of the production of public services and the requirement of client orientation; the problem of maintaining a consensus between the producer and consumer of public services in a constantly changing external environment; the problem of managing the import of a service model in conditions of catching up modernization. These problems should be solved basing on the application of the principles of sociology of management.
\end{abstract}

Keywords: state service, public service, transactional service, institutionalization of public service, patronage-service model of state, friendly service interface

БАЛАБАЙ Светлана Валерьевна - кандидат философских наук, доцент кафедры истории, философии, политологии и социологии Саратовского социально-экономического института - филиала Российского экономического университета им. Г.В. Плеханова (410003, Россия, г. Саратов, ул. Радищева, 89; narrativ63@mail.ru)

АБУБИКЕРОВА Эльмира Фаритовна - кандидат исторических наук, преподаватель кафедры истории, философии, политологии и социологии Саратовского социально-экономического института - филиала Российского экономического университета им. Г.В. Плеханова (410003, Россия, г. Саратов, ул. Радищева, 89)

\section{РОСТ ВЛИЯНИЯ ОБЫДЕННОГО СОЗНАНИЯ НА ПОЛИТИЧЕСКОЕ ПОВЕДЕНИЕ РОССИЯН}

Аннотация. В статье рассматривается социокультурный анализ феномена власти в контексте модусов времени, являющихся измерением общественного сознания. Взаимодействие власти и социума рассматривается в контексте иерархии форм общественного сознания. Авторы отмечают возрастание роли обыденного сознания в современной России. Это обеспечивает гибкое приспособление к обстоятельствам жизни, но существенно снижает рациональность политического поведения.

Ключевые слова: политическая власть, общественное сознание, социокультурный анализ, базовые ценности, политическое поведение

$\mathrm{P}$ езультаты прошедших выборов президента России вызвали некоторый шок у либеральной общественности. Для многих оппозиционных политиков и публицистов сверхвысокий процент голосов, полученный В.В. Путиным, никак не стыковался с низкими социально-экономическими показателями развития страны, ее внешнеполитической изоляцией и очевидным недоверием населения ко всей системе власти. При этом оппозиция не смогла обнаружить фальсификаций, существенным образом повлиявших на итоги выборов. Объяснить данный феномен, исходя только из анализа политической повседневности, 